\title{
Epoetin Biosimilars in the Treatment of Renal Anemia: What Have We Learned from a Decade of European Experience?
}

\author{
David Goldsmith ${ }^{1} \cdot$ Frank Dellanna $^{2} \cdot$ Martin Schiestl $^{3} \cdot$ Andriy Krendyukov $^{4}$ • \\ Christian Combe ${ }^{5,6}$
}

Published online: 2 March 2018

(C) The Author(s) 2018. This article is an open access publication

\begin{abstract}
Biosimilars are biological medicines that are approved via stringently defined regulatory pathways on the basis that comparable safety, efficacy, and quality have been demonstrated to their reference medicine. The advantage of biosimilar drugs is that they may be less expensive than the reference medicine, allowing for greater patient access and cost savings in already stretched healthcare budgets. Biosimilar epoetins have been available in Europe for a decade. Complementing in vitro and preclinical characterization, and pharmacokinetic/pharmacodynamic studies, clinical trials provided the additional data needed to reassure European authorities that biosimilar epoetins were sufficiently similar to the reference epoetin to warrant approval. Post-approval, real-world studies have provided further evidence that biosimilar epoetins are an effective and well-tolerated option for the treatment of renal anemia, with ongoing pharmacovigilance and observational studies monitoring for any unexpected long-term signals that have not been identified in clinical development studies. As the evidence and experience with these
\end{abstract}

Andriy Krendyukov

andriy.krendyukov@sandoz.com

1 Division of Nephrology, Guy's and St. Thomas' Hospitals, London, UK

2 MVZ Davita Rhein-Ruhr, Düsseldorf, Germany

3 Sandoz Biopharmaceuticals, Sandoz International GmbH, Kundl, Austria

4 Hematology/Nephrology, Sandoz Biopharmaceuticals, Hexal AG, Industriestr. 25, 83607 Holzkirchen, Germany

5 Service de Néphrologie Transplantation Dialyse Aphérèse, Centre Hospitalier Universitaire de Bordeaux, Bordeaux, France

6 Université de Bordeaux, INSERM 1026, Bordeaux, France products increase, many of the initial concerns are being alleviated. Nephrologists can be increasingly confident that European Medicines Agency-approved biosimilars offer high-quality, affordable, effective alternatives to existing reference medicines used to treat renal anemia, and may help yield cost savings and improve patient access.

\section{Key Points}

Evidence supporting the use of biosimilar epoetins has been acquired over more than 10 years since first approval in Europe.

Based on the available evidence and experience, nephrologists can be reassured that these medicines offer high-quality, affordable and effective alternatives to existing reference medicines used to treat renal anemia.

\section{Introduction}

Patients with chronic kidney disease (CKD) are at increased risk of anemia. In a study in the USA, anemia was twice as prevalent in patients with CKD (15.4\%), compared with the general population $(7.6 \%)$; the prevalence increased from $8.4 \%$ with CKD stage 1 to $53.4 \%$ with stage 5 [1]. Importantly, anemia in patients with CKD is associated with increased risk of health-related quality of life (HRQoL) impairment, cardiovascular disease, hospitalization, end-stage renal disease, and mortality, compared 
with CKD patients without anemia [2, 3]. Furthermore, direct healthcare costs are higher in CKD patients with anemia than in those without [4].

The introduction of recombinant human erythropoietin into clinical practice in the 1980s was a breakthrough in the treatment of renal anemia [5]. Initially, use of recombinant erythropoietin was limited to dialysis patients with the most severe forms of anemia; however, its use was subsequently extended to most dialysis patients with renal anemia and to predialysis patients, but only in countries in which the high cost of treatment did not limit access [5]. Following expiry of the European patent for the recombinant human erythropoietin, epoetin alfa, several biosimilar epoetins have been developed for the European market and licensed for use in the nephrology setting. Biosimilars are biological medicines that are approved via stringently defined regulatory pathways on the basis that comparable safety, efficacy, and quality has been demonstrated to their reference medicine. The advantage of biosimilar drugs is that they are less expensive than the reference medicine, allowing for greater patient access and cost savings in already stretched healthcare budgets [6]. This review outlines the regulatory process and requirements for biosimilar development and approval, discusses initial concerns raised about epoetin biosimilars by the nephrology community, describes clinical evidence gained, and discusses what can be learned from the European experience.

\subsection{Pathway for Development and Approval of Biosimilars}

Development, manufacture, and approval pathways are very different for biosimilars, compared with small-molecule generics, particularly as biological medicines (including biosimilars) are more complex molecules. The European Medicines Agency (EMA) was the first regulatory authority to establish legislative procedures for the approval of biosimilars when they published guidance in 2005 [7]. The EMA regulatory pathway for the approval of biosimilars is based on demonstrating comparable quality, safety, and efficacy to the reference medicine (Table 1) $[8,9]$. The EMA have also issued guidelines for specific product classes, including biosimilar epoetins [10].

The development of biosimilars is a systematic, iterative process involving several stages. Initially, the reference medicine is fully characterized to define its critical features and inherent variability, which are used as a "baseline" for development of the biosimilar [11]. A series of analytical assessments are conducted to ensure that the biosimilar has the same structural and functional properties as the reference medicine (Table 1) [11, 12]. Then may follow preclinical studies, for example, pharmaco-toxicological evaluations. Human clinical development usually includes phase 1 pharmacokinetics (PK) and pharmacodynamics (PD) studies to show bioequivalence, ideally in healthy volunteers. Finally, typically one confirmatory clinical phase 3 trial in a sensitive patient population is conducted to ensure that there are no meaningful differences in efficacy and safety between the biosimilar and reference medicines (Table 1).

Regulatory authorities will approve a proposed biosimilar only if similarity to the reference medicine is established based on the totality of evidence from the analytical, preclinical, and clinical development program [8, 13]. In some cases, bridging studies may be required by regulatory authorities to allow acceptance of development data generated with reference biologics licensed in a different territory [14]. When biosimilar comparability has been demonstrated, extrapolation to other indications of the reference medicine could be acceptable but needs to be scientifically justified and considered in light of all available (analytical, nonclinical, and clinical) data [9, 13, 15]. The scientific principles behind extrapolation of data are not new for biosimilars; they also apply to the comparison of approved products, before and after a change in the manufacturing process [16].

\subsection{Were Initial Concerns Raised by the Nephrology Community About Biosimilars Justified?}

Several concerns were initially raised by the nephrology community in relation to epoetin biosimilars, particularly regarding variability, quality, and safety.

\subsubsection{Variability and Quality}

Initial concerns that biosimilars may be highly variable and/or of substandard quality, compared with the licensed reference medicine, do not appear to be justified. A small degree of variability is common with any biological medicine, whether a reference medicine or a biosimilar, and batches are never identical to each other [16, 17]. It is interesting to note that any biological medicine will probably be modified several times throughout its life cycle [18]; such modifications typically arise due to changes in the manufacturing process. Such changes are small in most cases but can also be large (such as, in some cases, cell-line changes [19]). Therefore, current widely used biological medicines will technically not be identical to the originally approved version [16]. Regulatory authorities therefore require comparability data for the pre- and post-change product to ensure that any changes have no adverse effect on quality, clinical efficacy, and clinical safety [20]. This is known as a "comparability exercise", the underlying principles of which form the basis of the concept of biosimilarity. 
Table 1 Key points from the general EMA guidance for biosimilars [7, 8]

Definition of a biosimilar A biological medicinal product that contains a version of the active substance of an already authorized original biological medicine (reference medicinal product) in the EEA. Similarity to the reference medicinal product needs to be established based on a comprehensive comparability exercise (taking account of quality characteristics, biological activity, safety, and efficacy)

Choice of reference medicinal Must be a medicinal product authorized in the EEA, on the basis of a complete dossier in accordance with the product provisions of Article 8 of Directive 2001/83/EC, as amended

In some cases, it may be possible to compare the biosimilar in certain clinical and non-clinical studies with a non-EEA authorized medicinal product. The aim of this is to facilitate the global development of biosimilars and avoid unnecessary repetition of clinical trials

Non-clinical studies

\section{In vitro studies}

Data from several comparative studies should normally be provided in order to assess any potential differences in biological activity between the biosimilar and reference medicinal product

Studies should cover the entire spectrum of pharmacological and toxicological aspects

Studies should include relevant assays on:

Binding to target(s), for example, receptors known to be involved in the pharmacological effects of the reference medicine

Signal transduction and functional activity/viability of cells known to be of relevance for the pharmacotoxicological effects of the reference medicine and for the product class

In vitro assays are often more specific and sensitive to detect differences between a biosimilar and reference medicine than animal studies; therefore, these assays can be considered as most important for the non-clinical biosimilar comparability exercise

2. Determination of the need for in vivo studies

Factors to consider when assessing the need for in vivo non-clinical studies include:

Presence of potentially relevant quality attributes that have not been detected in the reference medicine, such as new post-translational modifications

Presence of potentially relevant quantitative differences in quality attributes between the biosimilar and the reference medicine

Relevant differences in formulation, such as use of excipients not widely used for biotechnology-derived proteins

3. In vivo studies

If these are deemed necessary, the focus (PK and/or PD and/or safety) depends on the additional information that is needed

Clinical studies

It is recommended that the clinical data required for the biosimilar comparability exercise are generated using the biosimilar product derived from the commercial manufacturing process

1. PK/PD studies

Comparative studies designed to demonstrate similar PK profile of the biosimilar and reference medicine are a key part of the biosimilar development program

Single-dose studies that fully characterize the PK profile are preferable

If the reference product can be administered IV and SC, evaluation of SC administration will usually be sufficient (as this covers absorption and elimination)

PD markers, selected on the basis of clinical relevance to the clinical outcome, should be added to the PK studies whenever feasible

2. Efficacy studies

Study populations should be representative of approved therapeutic indications of the reference medicine and be sensitive for detecting potential differences between the biosimilar and the reference

Equivalence study designs are preferred. Use of a non-inferiority design must be discussed with the regulatory authorities and justified with a strong scientific rationale

Studies are not intended to demonstrate the efficacy of a biosimilar per se (this has already been shown for the reference medicine); the purpose is to confirm comparable clinical performance of the biosimilar and the reference medicine

3. Clinical safety

Data should be captured during PK/PD studies as well as in pivotal clinical efficacy studies

Immunogenicity testing of the biosimilar and reference medicine should use the same assay format and sampling schedule. The incidence and nature of antibodies and antibody titers should be assessed and interpreted in relation to potential effects on clinical efficacy and safety 
Table 1 continued

\begin{tabular}{|c|c|}
\hline \multirow[t]{3}{*}{ Extrapolation of indications } & $\begin{array}{l}\text { When biosimilarity has been shown in one indication, extrapolation of clinical data to other indications of the } \\
\text { reference medicine is possible but needs to be scientifically justified }\end{array}$ \\
\hline & Extrapolation should be considered in light of the totality of data (quality, non-clinical, and clinical data) \\
\hline & $\begin{array}{l}\text { Immunogenicity may differ among indications; therefore, extrapolation of immunogenicity from the studied } \\
\text { indication / route of administration to other uses of the reference medicine should be justified }\end{array}$ \\
\hline Pharmacovigilance & $\begin{array}{l}\text { Clinical safety of biosimilars must be closely monitored on an ongoing basis following approval, including } \\
\text { continued benefit-risk assessment }\end{array}$ \\
\hline
\end{tabular}

EEA European Economic Area, EMA European Medicines Agency, $I V$ intravenous, $P K$ pharmacokinetic, $P D$ pharmacodynamic, $S C$ subcutaneous

Extensive characterization is conducted to establish that any microheterogeneity between a biosimilar and its reference medicine does not impact on clinical efficacy, or safety and immunogenicity. A recent study compared the quality and batch-to-batch variability of marketed epoetin reference medicines, Eprex ${ }^{\circledR} /$ Erypo $^{\circledR}$ (Janssen-Cilag, High Wycombe, UK) and NeoRecormon ${ }^{\circledR}$ (epoetin beta; Roche Registration Limited, Welwyn Garden City, UK), and two biosimilars, Binocrit ${ }^{\circledR}$ (Sandoz GmbH, Kundl, Austria) and Retacrit $^{\circledR}$ (Hospira UK Limited, Maidenhead, UK) [21]. All epoetin products were found to be of high quality, although there was some degree of variation among products and batches, confirming the "similar but not identical" paradigm of biologicals. Of note, biosimilar manufacturers are able to take advantage of state-of-the-art methodologies, which may not be used by manufacturers of reference medicines due to the financial and regulatory impact of changing from older processes [22].

In another study, the quality of Binocrit ${ }^{\circledR}$ and Retacrit ${ }^{\circledR}$ was found to be equal to that of the reference medicine, with partially lower levels of some impurities [23]. Unlike EMA-approved biosimilar epoetins, there are no assurances on the quality of "copy" biological epoetins manufactured in countries lacking rigorous regulations and standardized manufacturing processes [24, 25].

Qualitative and quantitative analysis of the reference epoetin alfa and two of its biosimilars revealed chemical differences were found only at the level of isoforms containing $\mathrm{N}$-glycosylation. However, functional in vivo and in vitro studies found no significant differences and confirmed the effective structural and functional similarity of the reference epoetin alfa and the biosimilars [26].

Comparisons of the epoetin area under concentrationtime curve (AUC) ratios demonstrate the pharmacokinetic equivalence of the reference epoetin alfa and biosimilar epoetins. The area under total concentration curve from 0-36 h at steady state $\left(\mathrm{AUC}_{\tau}\right)$ ratio of Binocrit ${ }^{\circledR}$ compared with the reference epoetin alfa was $89.2 \%$ [90\% confidence interval (CI) 82.5-96.2] [27]. An AUC ratio of $114.98 \%$ (90\% CI 110.49-119.66) was found between Binocrit ${ }^{\circledR}$ samples from the original production site and an additional production site. However, this level of variability falls within the standard bioequivalence boundaries of $80-125 \%$ [28]. This study also included comparisons of Binocrit ${ }^{\circledR}$ samples with a US-marketed epoetin alfa (Epogen ${ }^{\circledR}$, Amgen, Thousand Oaks, CA, USA) and the Europeanmarketed reference epoetin alfa $\left(\right.$ Eprex $^{\circledR} /$ Erypo $\left.^{\circledR}\right)$. An equivalent pharmacodynamic response was achieved with all compared epoetin alfa products, as confirmed by the hemoglobin AUEC ratio's 90\% CI falling within the predefined acceptance margins of 96.8-103.2\% [28].

\subsubsection{Safety, Including Immunogenicity}

As for any biological medicine, a key safety concern for biosimilars is immunogenicity. In rare cases, antibodies generated against exogenous erythropoietin may elicit hypersensitivity reactions, which can have a neutralizing effect and lead to pure red cell aplasia (PRCA) [17]. Human safety data are required for EMA approval of all biosimilars, including biosimilar epoetins [17], with at least 12 months of comparative immunogenicity results, using a validated and highly sensitive assay for anti-erythropoietin antibody detection [10]. None of the studies in the clinical program with HX575 or SB309, administered intravenously (IV), reported the presence of neutralizing antierythropoietin antibodies or any signs or symptoms consistent with PRCA [29, 30].

Subcutaneous (SC) administration of Eprex ${ }^{\circledR} /$ Erypo $^{\circledR}$ in patients with CKD was contraindicated in the European Union (EU), between 2002 and 2006, after increased reports of PRCA [31]. After 2006, the incidence of PRCA dropped substantially when the manufacturer replaced uncoated with coated rubber stoppers and reinforced the cold chain. SC use was subsequently reinstated, allowing a comparative study of SC HX575 and Eprex ${ }^{\circledR} /$ Erypo $^{\circledR}$ in 
renal anemia to be conducted; however, two patients developed neutralizing anti-erythropoietin antibodies following SC administration of HX575 in this trial [32]. A thorough root-cause analysis indicated that immunogenic reactions were precipitated by increased tungsten exposure and associated protein aggregation in pre-filled syringes with a small number of study drug batches [33, 34]. The manufacturing process was subsequently improved to reduce tungsten levels (introduction of low-tungsten syringes) and, following the completion of an open-label, single-arm study in pre-dialysis and dialysis patients in which no patients developed neutralizing antibodies [35], HX575 was approved by the EMA for SC administration in the nephrology indication in March 2016 [36].

Several cases of PRCA have been reported following the use of "copy" biological epoetins in Latin America and Asia. These alternative biologic products vary in composition and typically do not follow a rigorous development and approval process, such as the one mandated by the EMA in Europe [37, 38]. When cases of PRCA do occur, identifying the treatment that caused the condition is a potential issue in patients who have been switched from one drug to another. In addition to the rigorous development and approval process for biosimilars in Europe, postmarketing and risk management pharmacovigilance plans must be submitted for biosimilar epoetins [39]. After biosimilars are approved, companies are also required to submit periodic safety reports.

There have also been concerns raised about potential safety risks associated with switching to and from biosimilar products [40]. A retrospective drug utilization study conducted in Italy quantified the occurrence of switching between different epoetins [41]. The probability of switching was associated with the duration of treatment: about $15 \%$ of users switched within 12 months and almost $25 \%$ within 2 years of observation. Switching was not restricted to the replacement of reference epoetins with biosimilar epoetins but also extended to products that have not been directly compared in clinical studies. The authors concluded that the level of switching may provide reassurance to physicians when taken together with other sources of comparative evidence [41]. A review of data from clinical trials, pharmacovigilance databases, and an overview of the literature on the frequency of switching, assessed both switching between reference medicines within the same product class and switching to and from biosimilars. No evidence was found to suggest that switching to and from different biologicals leads to safety concerns [40].

A retrospective analysis of stable adult hemodialysis patients $(n=326)$ has reported that switching from the reference epoetin to a biosimilar may incur a dose penalty [42]. However, this report is inconsistent with other published data. These include a population-based analysis of real-world data from ambulatory patients $(n=6117)$ with CKD undergoing maintenance hemodialysis [43], and a large post-approval study of IV HX575 in patients $(n=1695)$ with CKD [44].

\subsection{Summary of Clinical Data Available for Biosimilar Epoetins in Europe}

Two biosimilar epoetins (marketed under five brand names) have been approved by the EMA and are currently available in Europe (Table 2). HX575 is a biosimilar version of Eprex $^{\circledR} /$ Erypo $^{\circledR}$ and, in 2007 , became the first biosimilar epoetin to be approved in Europe. HX575 has the same international non-proprietary name (INN) as epoetin alfa and is marketed as Binocrit ${ }^{\circledR}$ (Sandoz GmbH, Kundl, Austria), Epoetin alfa $\operatorname{HEXAL}^{\circledR}$ (Hexal AG, Holzkirchen, Germany), and Abseamed $^{\circledR}$ (Medice Arzneimittel Pütter GmbH \& Co. KG, Iserlohn, Germany). SB309 is a biosimilar epoetin that also has Eprex ${ }^{\circledR} /$ Erypo $^{\circledR}$ as its reference medicine but has the INN epoetin zeta. It is marketed as Retacrit ${ }^{\circledR}$ (Hospira UK Limited, Maidenhead, UK) and Silapo ${ }^{\circledR}$ (Stada Arzneimittel AG, Bad Vilbel, Germany).

Figure 1 gives an overview of key clinical studies performed with biosimilar epoetins in Europe. Complementing the in vitro and preclinical characterization, and PK/PD studies, these clinical trials provided the additional data needed to reassure European authorities that HX575 and SB309 were sufficiently similar to reference epoetin to warrant approval as biosimilar agents.

Several phase 1 PK and PD studies have been conducted with SB309 and HX575, and these have all shown profiles that are similar to the reference medicine [29, 30]. Two phase 3 randomized trials compared the efficacy of IV SB309 and reference epoetin alfa in patients with CKDinduced anemia and therapeutic equivalence was demonstrated in both studies [45, 46]. In one of these studies, 609 patients with CKD and anemia (hemoglobin $[\mathrm{Hb}]<9 \mathrm{~g} / \mathrm{dl}$ ) received either SB309 or Eprex ${ }^{\circledR} /$ Erypo $^{\circledR}$ IV for 24 weeks [45]. Mean (standard deviation [SD]) $\mathrm{Hb}$ concentration over the last 4 weeks of treatment was $11.61(1.27) \mathrm{g} / \mathrm{dl}$ with SB309 and $11.63(1.37) \mathrm{g} / \mathrm{dl}$ with reference epoetin alfa (95\% CI -0.25 to 0.20$)$. The most commonly reported adverse events (AEs; $>5 \%$ of patients) by System Organ Class were infections and infestations $(12.5 \%$ and $12.8 \%$ of patients treated with SB309 and reference epoetin alfa, respectively) and vascular disorders (8.5 and 8.9\%, respectively). No patients developed neutralizing anti-erythropoietin antibodies. After receiving authorization for IV administration, a later premarket authorization randomized trial assessed the therapeutic equivalence of SC SB309 and reference epoetin alfa [47]. This study showed therapeutic 
Table 2 Erythropoiesis-stimulating agents currently available in Europe

\begin{tabular}{|c|c|c|c|c|c|c|c|}
\hline \multirow[t]{2}{*}{ Characteristic } & \multicolumn{7}{|l|}{ Company } \\
\hline & $\begin{array}{l}\text { Sandoz, } \\
\text { Hexal, } \\
\text { Medice } \\
\text { Arzneimittel }\end{array}$ & Hospira, STADA & Teva & $\begin{array}{l}\text { J\&J } \\
\text { (Janssen- } \\
\text { Cilag) }\end{array}$ & Roche & Amgen & Roche \\
\hline INN & $\begin{array}{l}\text { Epoetin alfa } \\
\text { (biosimilar) }\end{array}$ & $\begin{array}{l}\text { Epoetin zeta } \\
\text { (biosimilar) }\end{array}$ & $\begin{array}{l}\text { Epoetin } \\
\text { theta }\end{array}$ & $\begin{array}{l}\text { Epoetin } \\
\text { alfa }\end{array}$ & $\begin{array}{l}\text { Epoetin } \\
\text { beta }\end{array}$ & $\begin{array}{l}\text { Darbepoetin } \\
\text { alfa }\end{array}$ & $\begin{array}{l}\text { Methoxy polyethylene glycol- } \\
\text { epoetin beta }\end{array}$ \\
\hline $\begin{array}{l}\text { Year of first } \\
\text { launch }\end{array}$ & 2007 & 2008 & 2010 & 1989 & 1990 & 2001 & 2007 \\
\hline $\begin{array}{l}\text { Route of } \\
\text { administration }\end{array}$ & IV, SC & IV, SC & IV, SC & IV, SC & IV, SC & IV, SC & IV, SC \\
\hline
\end{tabular}

$I N N$ international non-proprietary name, $I V$ intravenous, $S C$ subcutaneous

equivalence in maintaining target $\mathrm{Hb}$ levels and in safety profiles.

For HX575, a phase 3 maintenance study was conducted versus reference medicine in adult dialysis patients and therapeutic equivalence was demonstrated [30, 48]. Hemodialysis patients with $\mathrm{Hb}$ levels of $10.0-13.0 \mathrm{~g} / \mathrm{dl}$ received either HX575 or Eprex ${ }^{\circledR} /$ Erypo $^{\circledR}$ IV, one to three times per week for 28 weeks [48]. Mean changes in $\mathrm{Hb}$ levels were $0.15(0.09) \mathrm{g} / \mathrm{dl}$ with HX575 and $0.06(0.12)$ $\mathrm{g} / \mathrm{dl}$ with reference epoetin alfa, with a difference between groups of $0.08 \mathrm{~g} / \mathrm{dl}(95 \% \mathrm{CI}-0.17$ to 0.34$)$. The long-term safety profile of HX575 was similar to that of the reference epoetin alfa. No patients developed neutralizing anti-erythropoietin antibodies. In the open-label, single-arm registration study of SC HX575 in 416 pre-dialysis and dialysis patients, HX575 was effective in managing anemia, regardless of whether they had previously been treated with epoetins, with no clinical signs of immunogenicity or hypersensitivity with SC administration [35].

Several post-authorization studies have and are being conducted to provide long-term effectiveness and safety data, particularly the incidence of less frequently experienced AEs, which may not be detected in shorter, smaller registration studies. One example is the post-marketing EPO-PASS study of IV HX575, involving more than 1700 patients with renal anemia [44]. The study period covered 770 patient-years. The observed AE profile was in line with expectations for this patient population. No subject developed anti-epoetin antibodies. Thrombotic vascular events were reported in $11.9 \%$ of patients $(0.2612$ per patientyear). Tumor incidence was $1.4 \%$ (0.0299 per patientyear). Mean $\mathrm{Hb}$ levels were effectively maintained between 11.2 and $11.3 \mathrm{~g} / \mathrm{dl}$ following the conversion from a broad spectrum of pre-study, erythropoiesis-stimulating agent (ESA) treatments with stable overall mean IV HX575 doses. The proportion of patients within the $\mathrm{Hb}$ target range increased from $57.5 \%$ at baseline to $66.8 \%$ at study end.
Safety findings have been reported for the PASCO I study with IV SB309 in 1634 patients with renal anemia over a 1-year study observation period [50]. The frequency of AEs of special interest was comparable with data for other existing epoetin products: clotting of artificial kidney, 9.8\%; lack of efficacy, $2.3 \%$; cerebrovascular events, $1.8 \%$; myocardial infarction, $1.7 \%$; acute myocardial infarction, $1.2 \%$; clinically relevant hyperkalemia, $0.4 \%$; deep vein thrombosis, $0.2 \%$; convulsion, $0.2 \%$; hypertensive encephalopathy, $0.1 \%$; and pulmonary embolism, $0.1 \%$. No patients were reported as having anaphylactoid reactions, angioedema, erythropoietin-neutralizing antibodies, or PRCA.

Data and experience continue to accumulate for biosimilar epoetins in renal anemia. A population-based study compared the effects of the reference epoetin Eprex $^{\circledR} /$ Erypo $^{\circledR}$ with three biosimilars $\left(\right.$ Binocrit $^{\circledR}$, Abseamed $^{\circledR}$ and Retacrit $^{\circledR}$ ) in 583 patients with CKD. There was no statistically significant difference among the reference medicine and biosimilars in dose dispensed, and the efficacy and safety of the epoetin biosimilars were found to be equivalent to that of the reference medicine [51]. In another population-based observational study of 8161 patients with CKD, no differences between the reference medicine and biosimilars were found with regard to the risk of all-cause mortality, blood transfusion, major cardiovascular events and blood dyscrasia [52]. Taken together, these data provide evidence of effectiveness and reassurance that there have been no unexpected safety signals with the real-world use of biosimilar epoetins.

\subsection{What Can Be Learned from the European Experience?}

The first biosimilar product was approved in the EU in 2006, with the first biosimilar epoetin following in 2007 [53]. Despite some initial reluctance, the adoption of biosimilar epoetins continues to grow, although there is 
$\underline{\text { SB309 }}$

\begin{tabular}{|c|}
\hline $\begin{array}{c}\text { PK/PD studies } \\
\text { (healthy subjects) }\end{array}$ \\
\hline
\end{tabular}

Clinical efficacy I safety (pre-approval)

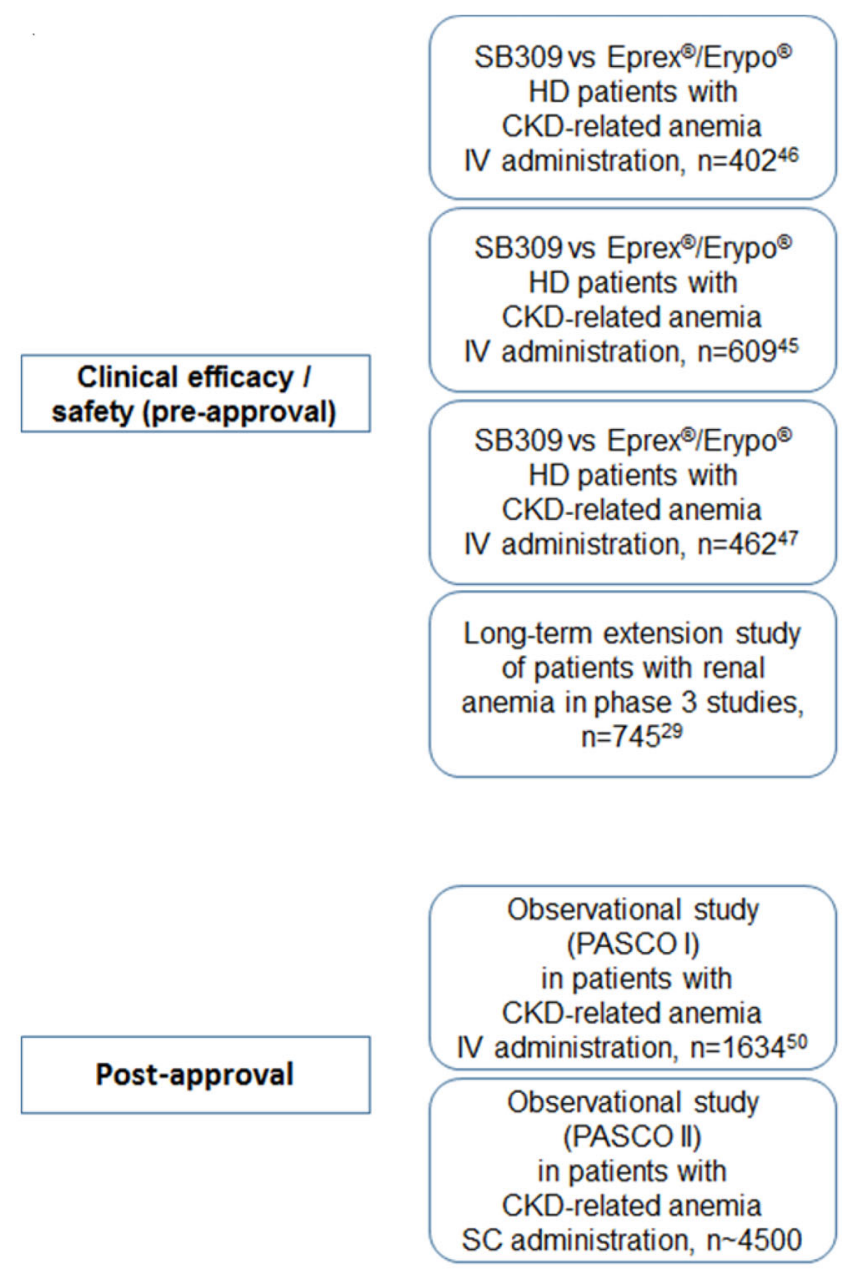

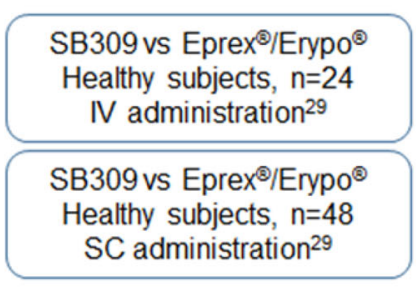
HX575 vs Eprex ${ }^{\circledast} /$ Erypo $^{\circledR}$
Healthy subjects, $n=80$
IV administration ${ }^{30}$

HX575 vs Eprex ${ }^{\circledast} /$ Erypo $^{\circledR}$

Healthy subjects, $n=80$

IV administration ${ }^{30}$

HX575 vs NeoRecormon ${ }^{\circledR}$

Healthy subjects, $n=80$

SC administration ${ }^{30}$
HX575 vs Eprex ${ }^{\circledast}$ Erypo $^{\odot}$

HD patients with

CKD-related anemia

IV administration, $n=479^{48}$

HX575

Patients with

CKD-related anemia

$\mathrm{SC}$ administration, $\mathrm{n}=417^{35}$

Fig. 1 Key clinical studies of biosimilar epoetins in Europe $[29,30,35,44-50] . P K$ pharmacokinetic, $P D$ pharmacodynamic, $I V$ intravenous, $S C$ subcutaneous, $C K D$ chronic kidney disease, $H D$ hemodialysis

some variation in uptake across countries [25, 38]. In ten European countries (seven Western and three Central/ Eastern), biosimilar epoetins have a market share of $>25 \%$, including five countries (three Western and two Central/ Eastern) at $\geq 50 \%$. The variation in uptake is probably due to different cost pressures across the healthcare systems, different cost-containment measures, and the presence or absence of healthcare policies driving biosimilar adoption [38]. For example, in France there was no pressure to reduce costs associated with ESA therapy up until the end of 2013. Since then, the cost of ESAs has been included in dialysis fees and this may result in greater adoption of biosimilar medicines. 
It has been estimated that the availability of biosimilar ESAs in Germany provided a saving of $€ 60$ million during their first year on the market. This saving comprised the lower price of the biosimilars and also price reductions for reference medicines [38, 54]. The same study projected potential savings through biosimilar use of $€ 8$ billion in Germany alone up to 2020 .

Following EU availability, biosimilar epoetins have been approved in Australia in 2010 and in New Zealand in 2013 [39]. In the USA, guidelines on scientific and quality considerations in demonstrating biosimilarity were issued by the Food and Drug Administration (FDA) in 2015, following the enactment of the Biologics Price Competition and Innovation Act in 2010 [13, 55, 56]. In general, the FDA has developed a similar biosimilar approval pathway as in the EU, involving clear demonstration that the biosimilar product is highly similar to an FDA-approved reference medicine and has no clinically meaningful differences in terms of safety and effectiveness. Only minor differences in clinically inactive components are permitted in biosimilar products. The FDA regulatory pathway also includes the option for a regulatory designation on interchangeability, which refers, in the USA, to the ability to automatically substitute a medicine at the pharmacy level, and which requires additional data for biosimilarity alone [13]. Draft guidance on considerations in demonstrating interchangeability with a reference medicine was published in January 2017 [57]. EU regulators have stated that EUapproved biosimilars are considered medically interchangeable; this refers, in the $\mathrm{EU}$, to the practice of changing one medicine for another that is expected to achieve the same clinical effect in a given clinical setting and in any patient, with the agreement of the prescriber [58]. In the EU, decisions on automatic substitution between a biological reference medicine and its biosimilar is upon the mandate of individual member states [10, 39].

The first biosimilar product to be approved by the FDA under the new regulatory pathway was Zarxio ${ }^{\circledR}$ (filgrastimsndz; Sandoz GmbH, Kundl, Austria) in March 2015, with approval granted for all the same indications as the reference medicine, Neupogen ${ }^{\circledR}$ (Amgen Europe B.V, Breda, The Netherlands) [59]. The expiry of patents in 2014 potentially opens the USA market to biosimilar epoetins; submissions have been made to the FDA, and the Oncology Drugs Advisory Committee (ODAC) recently recommended approval of a proposed biosimilar epoetin alfa [60]. If approved, the provision of adequate education to payers, healthcare professionals, and patients regarding the biosimilar concept will be important for their acceptance [56]; however, reassurance may be provided from the decade of experience gained in Europe for biosimilar epoetins.

\section{Summary}

Biosimilars, including biosimilar epoetin alfas, have now been available in Europe for 10 years and their use is becoming more widespread. As of April 2016, Binocrit ${ }^{\circledR}$ has generated more than 400,000 patient-years of experience worldwide (in CKD and chemotherapy-induced anemia) [31]. These agents are approved only if extensive analytical and clinical testing demonstrates comparable quality, safety, and efficacy to the reference medicine. Real-world studies provide further evidence that biosimilar epoetins are an effective and well tolerated option for the treatment of renal anemia, with ongoing pharmacovigilance and observational studies, monitoring for any unexpected long-term signals that have not been identified in clinical development studies.

Europe has led the way with their rigorous biosimilar approval pathway; other countries have used the lessons learned in Europe to develop their own processes and, as such, biosimilar epoetins are now available across many countries and regions. Expansion into the USA market is now likely, following the recent positive opinion of the FDA ODAC on a proposed biosimilar epoetin alfa; assuming full approval follows, additional experience will be gained in this large market, where the proportion affected by renal anemia is high. As the evidence and experience with these products increase, many of the initial concerns are being alleviated. Nephrologists can be increasingly confident that biosimilars offer high-quality, affordable, effective alternatives to existing reference medicines used to treat anemia, and may help yield cost savings and improve patient access.

\section{Compliance with Ethical Standards}

Funding Editorial support was provided by Tony Reardon of Spirit Medical Communications Ltd., supported by Hexal AG/Sandoz International $\mathrm{GmbH}$.

Conflict of Interest DG, FD, and CC have served as advisors to Sandoz (study Steering Committee members). MS and AK are employees of Sandoz International GmbH/Hexal AG.

Ethics approval This article does not contain any studies with human participants or animals performed by any of the authors.

Open Access This article is distributed under the terms of the Creative Commons Attribution-NonCommercial 4.0 International License (http://creativecommons.org/licenses/by-nc/4.0/), which permits any noncommercial use, distribution, and reproduction in any medium, provided you give appropriate credit to the original author(s) and the source, provide a link to the Creative Commons license, and indicate if changes were made. 


\section{References}

1. Stauffer ME, Fan T. Prevalence of anemia in chronic kidney disease in the United States. PLoS One. 2014;9:e84943.

2. Li S, Foley RN, Collins AJ. Anemia and cardiovascular disease, hospitalization, end stage renal disease, and death in older patients with chronic kidney disease. Int Urol Nephrol. 2005;37:395-402.

3. Eriksson D, Goldsmith D, Teitsson S, Jackson J, van Nooten F. Cross-sectional survey in CKD patients across Europe describing the association between quality of life and anaemia. BMC Nephrol. 2016;17:97.

4. van Nooten FE, Green J, Brown R, Finkelstein FO, Wish J. Burden of illness for patients with non-dialysis chronic kidney disease and anemia in the United States: review of the literature. J Med Econ. 2010;13:241-56.

5. KDIGO. Chapter 3: Use of ESAs and other agents to treat anemia in CKD. Kidney Int Suppl. 2012;2:299-310.

6. Wish JB. The approval process for biosimilar erythropoiesisstimulating agents. Clin J Am Soc Nephrol. 2014;9:1645-51.

7. European Medicines Agency. Guideline on similar biological medicinal products. 2005. http://www.ema.europa.eu/docs/en GB/document_library/Scientific_guideline/2009/09/WC5000035 17.pdf. Accessed 25 Jan 2018.

8. European Medicines Agency. Guideline on similar biological medicinal products. 2014. http://www.ema.europa.eu/docs/en GB/document_library/Scientific_guideline/2014/10/WC5001767 68.pdf. Accessed 25 Jan 2018.

9. European Medicines Agency. Guidelines on similar biological medicinal products containing biotechnology-derived proteins as active substance: non-clinical and clinical issues. 2014. http:// www.ema.europa.eu/docs/en_GB/document_library/Scientific_ guideline/2015/01/WC500180219.pdf Accessed 25 Jan 2018.

10. European Medicines Agency. Guideline on non-clinical and clinical development of similar biological medicinal products containing recombinant erythropoietins (Revision). 2010. http:// www.ema.europa.eu/docs/en_GB/document_library/Scientific_ guideline/2010/04/WC500089474.pdf Accessed 25 Jan 2018.

11. McCamish M, Woollett G. The state of the art in the development of biosimilars. Clin Pharmacol Ther. 2012;91:405-17.

12. Holzmann J, Balser S, Windisch J. Totality of the evidence at work: the first US biosimilar. Expert Opin Biol Ther. 2016;16:137-42.

13. US Food and Drug Administration. Biosimilarity guidelines. November 2015. http://www.fda.gov/Drugs/GuidanceComplia nceRegulatoryInformation/Guidances/ucm290967.htm. Accessed 14 June 2017.

14. Webster CJ, Woollett GR. A 'global reference' comparator for biosimilar development. BioDrugs. 2017;31:279-86.

15. Curigliano G, O'Connor DP, Rosenberg JA, Jacobs I. Biosimilars: extrapolation for oncology. Crit Rev Oncol Hematol. 2016;104:131-7.

16. Weise M, Kurki P, Wolff-Holz E, Bielsky M-C, Schneider CK. Biosimilars: the science of extrapolation. Blood. 2014;124:3191-6.

17. Weise M, Bielsky MC, De Smet K, et al. Biosimilars: what clinicians should know. Blood. 2012;120:5111-7.

18. Schneider CK. Biosimilars in rheumatology: the wind of change. Ann Rheum Dis. 2013;72:315-8.

19. European Medicines Agency. European public assessment report variation, Aranesp-H-332-X-42. 2008. http://www.ema.europa.eu/ docs/en_GB/document_library/EPAR_-_Assessment_Report_-_ Variation/human/000332/WC500026148.pdf. Accessed 14 June 2017.
20. ICH. ICH harmonized tripartite guideline: comparability of biotechnological/biological products subject to changes in their manufacturing process Q5E. 2004. http://www.ich.org/fileadmin/ Public_Web_Site/ICH_Products/Guidelines/Quality/Q5E/Step4/ Q5E_Guideline.pdf. Accessed 14 June 2017.

21. Halim LA, Brinks V, Jiskoot W, et al. Quality and batch-to-batch consistency of original and biosimilar epoetin products. J Pharm Sci. 2016;105:542-50.

22. Schellekens H, Moors E. Clinical comparability and European biosimilar regulations. Nat Biotechnol. 2010;28:28-31.

23. Brinks V, Hawe A, Basmeleh AH, et al. Quality of original and biosimilar epoetin products. Pharm Res. 2011;28:386-93.

24. Combe C, Tredree RL, Schellekens H. Biosimilar epoetins: an analysis based on recently implemented European medicines evaluation agency guidelines on comparability of biopharmaceutical proteins. Pharmacother J Hum Pharmacol Drug Ther. 2005;25:954-62.

25. Covic A, Abraham I. State-of-the-art biosimilar erythropoietins in the management of renal anemia: lessons learned from Europe and implications for US nephrologists. Int Urol Nephrol. 2015;47:1529-39.

26. Gianoncelli A, Bonini SA, Bertuzzi M, et al. An integrated approach for a structural and functional evaluation of biosimilars: implications for erythropoietin. BioDrugs. 2015;29:285-300.

27. Sorgel F, Thyroff-Friesinger U, Vetter A, et al. Bioequivalence of HX575 (recombinant human epoetin alfa) and a comparator epoetin alfa after multiple intravenous administrations: an openlabel randomised controlled trial. BMC Clin Pharmacol. 2009;9:10.

28. Lissy M, Ode M, Roth K. Comparison of the pharmacokinetic and pharmacodynamic profiles of one US-marketed and two European-marketed epoetin alfas: a randomized prospective study. Drugs R D. 2011;11:61-75.

29. European Medicines Agency. Retacrit scientific discussion. 2007. http://www.ema.europa.eu/docs/en_GB/document_library/EPAR_Scientific_Discussion/human/000872/WC500054374.pdf. Accessed 14 June 2017.

30. European Medicines Agency. Binocrit scientific discussion. 2007. http://www.ema.europa.eu/docs/en_GB/document_library/EPAR_Scientific_Discussion/human/000725/WC500053615.pdf. Accessed 14 June 2017.

31. Macdougall IC, Casadevall N, Locatelli F, et al. Incidence of erythropoietin antibody-mediated pure red cell aplasia: the Prospective Immunogenicity Surveillance Registry (PRIMS). Nephrol Dial Transplant. 2015;30:451-60.

32. Haag-Weber M, Eckardt KU, Hörl WH, Roger SD, Vetter A, Roth K. Safety, immunogenicity and efficacy of subcutaneous biosimilar epoetin- $\alpha$ (HX575) in non-dialysis patients with renal anemia: a multi-center, randomized, double-blind study. Clin Nephrol. 2012;77:8-17.

33. Seidl A, Hainzl O, Richter M, et al. Tungsten-induced denaturation and aggregation of epoetin alfa during primary packaging as a cause of immunogenicity. Pharm Res. 2012;29:1454-67.

34. Rubic-Schneider T, Kuwana M, Christen B, et al. T-cell assays confirm immunogenicity of tungsten-induced erythropoietin aggregates associated with pure red cell aplasia. Blood Adv. 2017;1:367-79.

35. Casadevall N, Dobronravov V, Eckardt KU, et al. Evaluation of the safety and immunogenicity of subcutaneous HX575 epoetin alfa in the treatment of anemia associated with chronic kidney disease in predialysis and dialysis patients. Clin Nephrol. 2017;88:190-7.

36. Novartis. Press release: Sandoz receives EC approval for subcutaneous route of administration in biosimilar Binocrit' ${ }^{\circledR}$ nephrology indication. 2016. https://www.novartis.com/news/ 
media-releases/sandoz-receives-ec-approval-subcutaneous-routeadministration-biosimilar. Accessed 14 June 2017.

37. Praditpornsilpa K, Tiranathanagul K, Kupatawintu $\mathrm{P}$, et al. Biosimilar recombinant human erythropoietin induces the production of neutralizing antibodies. Kidney Int. 2011;80:88-92.

38. Goldsmith D, Gesualdo L. Biosimilar epoetins in nephrologywhere are we now? Eur Nephrol. 2012;6:21-4.

39. Leung LK, Mok K, Liu C, Chan SL. What do oncologists need to know about biosimilar products? Chin J Cancer. 2016;35:91.

40. Ebbers HC, Muenzberg M, Schellekens H. The safety of switching between therapeutic proteins. Expert Opin Biol Ther. 2012;12:1473-85.

41. D'Amore C, Da Cas R, Rossi M, Traversa G. Switching between epoetins: a practice in support of biosimilar use. BioDrugs. 2016;30:27-32.

42. Minutolo R, Bolasco P, Chiodini P, et al. Effectiveness of switch to erythropoiesis-stimulating agent (ESA) biosimilars versus maintenance of ESA originators in the real-life setting: matchedcontrol study in hemodialysis patients. Clin Drug Investig. 2017;37:965-73.

43. Hörbrand F, Bramlage P, Fischaleck J, Hasford J, Brunkhorst R. A population-based study comparing biosimilar versus originator erythropoiesis-stimulating agent consumption in 6,117 patients with renal anaemia. Eur J Clin Pharmacol. 2013;69:929-36.

44. Hörl WH, Locatelli F, Haag-Weber M, Ode M, Roth K, EpoPASS Study Group. Prospective multicenter study of HX575 (biosimilar epoetin- $\alpha$ ) in patients with chronic kidney disease applying a target hemoglobin of $10-12 \mathrm{~g} / \mathrm{dl}$. Clin Nephrol. 2012;78:24-32.

45. Krivoshiev S, Todorov VV, Manitius J, et al. Comparison of the therapeutic effects of epoetin zeta and epoetin alpha in the correction of renal anaemia. Curr Med Res Opin. 2008;24:1407-15.

46. Wizemann V, Rutkowski B, Baldamus C, Scigalla P, Koytchev R, Epoetin Zeta Study Group. Comparison of the therapeutic effects of epoetin zeta to epoetin alfa in the maintenance phase of renal anaemia treatment. Curr Med Res Opin. 2008;24:625-37.

47. Krivoshiev S, Wizemann V, Czekalski S, et al. Therapeutic equivalence of epoetin zeta and alfa, administered subcutaneously, for maintenance treatment of renal anemia. Adv Ther. 2010;27:105-17.

48. Haag-Weber M, Vetter A, Thyroff-Friesinger U, INJ-Study Group. Therapeutic equivalence, long-term efficacy and safety of HX575 in the treatment of anemia in chronic renal failure patients receiving hemodialysis. Clin Nephrol. 2009;72:380-90.

49. London G, Mann J, Goldsmith D, et al. Long-term treatment with biosimilar epoetin- $\alpha$ (HX575) in hemodialysis patients with renal anemia: real-world effectiveness and safety in the MONITORCKD5 study. Clin Nephrol. 2018;89:1-9.

50. Dellanna F, Fluck RJ, Lonnemann G, Wild CA, Iwanowitsch A, Meissner R, Audhya P. Results from a safety cohort of patients with renal anemia receiving the biosimilar epoetinzeta: the PASCO I study. Clin Nephrol. 2015;84:280-8.

51. Ingrasciotta Y, Giorgianni F, Marciano I, et al. Comparative effectiveness of biosimilar, reference product and other Erythropoiesis-Stimulating Agents (ESAa) still covered by patent in chronic kidney disease and cancer patients: an italian populationbased study. PLoS One. 2016;17(11):5.

52. Trotta F, Belleudi V, Fusco D, et al. Comparative effectiveness and safety of erythropoiesis-stimulating agents (biosimilars vs originators) in clinical practice: a population-based cohort study in Italy. BMJ Open. 2017;7:e011637.53. GaBI Online. Biosimilars approved in Europe: June 2017 update. 2017. http://www. gabionline.net/Biosimilars/General/Biosimilars-approved-in-Europe. Accessed 14 June 2017.

53. IGES Institute. The competitive role of biosimilars in the German SHI market for pharmaceuticals. 2010.

54. Lemery SJ, Ricci MS, Keegan P, McKee AE, Pazdur R. FDA's approach to regulating biosimilars. Clin Cancer Res. 2017;23:1882-5.

55. Wish JB, Charytan C, Chertow GM, et al. Introduction of biosimilar therapeutics into nephrology practice in the United States: report of a scientific workshop sponsored by the National Kidney Foundation. Am J Kidney Dis. 2016;68:843-52.

56. US Food and Drug Administration. Considerations in demonstrating interchangeability with a reference product. Guidance for industry: draft guidance. 2017. http://www.fda.gov/downloads/ Drugs/GuidanceComplianceRegulatoryInformation/Guidances/ UCM537135.pdf. Accessed 14 June 2017.

57. Kurki P, van Aerets L, Wolff-Holz E, Giezen T, Skibeli V, Weise M. Interchangeability of biosimilars: a European perspective. BioDrugs. 2017;31:83-91.

58. US Food and Drug Administration. Filgrastim-sndz. 2015. https:// www.fda.gov/newsevents/newsroom/pressannouncements/ucm 43 6648.htm. Accessed 16 Dec 2016.

59. US Food and Drug Administration. Briefing Document: BLA125545 "Epoetin Hospira", a proposed biosimilar to Epogen/Procrit (epoetin alfa). 2017. https://www.fda.gov/downloads/ AdvisoryCommittees/CommitteesMeetingMaterials/Drugs/Oncolo gicDrugsAdvisoryCommittee/UCM559967.pdf. Accessed 14 June 2017. 